\title{
New Dihydrothiazole Benzensulfonamides: Looking for Selectivity toward Carbonic Anhydrase Isoforms I, II, IX, and XII
}

\author{
Rita Meleddu, Simona Distinto,* Filippo Cottiglia, Rossella Angius, Pierluigi Caboni, Andrea Angeli, \\ Claudia Melis, Serenella Deplano, Stefano Alcaro, Francesco Ortuso, Claudiu T. Supuran,* \\ and Elias Maccioni
}

Cite This: ACS Med. Chem. Lett. 2020, 11, 852-856

Read Online

ACCESS | 네 Metrics \& More | 回 Article Recommendations | sl Supporting Information

ABSTRACT: In the present study we investigated the structureactivity relationships of a new series of 4-[(3-ethyl-4-aryl-2,3dihydro-1,3-thiazol-2-ylidene) amino] benzene-1-sulfonamides $($ EMAC10101a-m). All synthesized compounds, with the exception of compound EMAC10101k, preferentially inhibit offtarget hCA II isoform. Within the series, compound EMAC10101d, bearing a 2,4-dichorophenyl substituent in position 4 of the dihydrothiazole ring, was the most potent and selective toward hCA II with an inhibitory activity in the low nanomolar range.

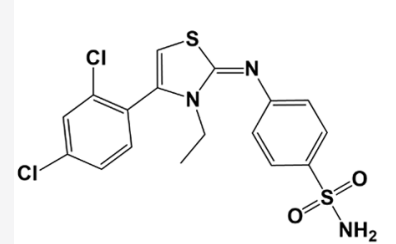

EMAC10101d

hCAll Ki $8.1 \mathrm{nM}$

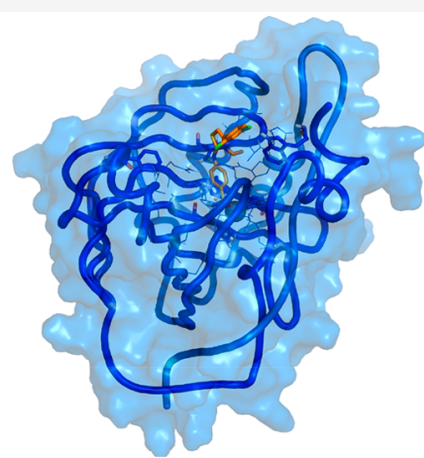

KEYWORDS: Dual enzyme inhibitors, carbonic anhydrase, anticancer agents, docking, benzensulfonamides

$\mathrm{H}$ uman carbonic anhydrases (hCAs) belongs to a family of ubiquitous metalloenzymes that catalyze an essential yet simple physiological reaction, the reversible hydration of carbon dioxide to bicarbonate and protons $\left(\mathrm{CO}_{2}+\mathrm{H}_{2} \mathrm{O} \leftrightarrows\right.$ $\left.\mathrm{HCO}_{3}{ }^{-}+\mathrm{H}^{+}\right)$. Sixteen different $\alpha$-CA isozymes or CA-related proteins (CARPs) were identified and described so far differing in cellular localization and tissue distribution. ${ }^{1,2}$ Thus, cytosolic forms (hCA I-III, VII), membrane-bound (hCA IV, IX, XII, and XIV), mitochondrial form (hCA V), and secreted (hCA VI) isozymes can be distinguished. ${ }^{1}$ According to their cellular and tissue localization, hCAs are involved in crucial physiological processes such as respiration and transport of $\mathrm{CO}_{2} /$ bicarbonate between metabolizing cell/tissues and lungs, $\mathrm{pH}$ and $\mathrm{CO}_{2}$ homeostasis, bone resorption, calcification, electrolyte secretion in a variety of tissues/organs, biosynthetic reactions (such as gluconeogenesis, lipogenesis, and ureagenesis), and tumor genesis and progression. ${ }^{1,3-8}$ Not surprisingly the physiological and pathological role of hCA has been extensively studied and the role of potential inhibitors and/or activators investigated, ${ }^{9,10}$ in particular the implication of hCAs IX and XII in different types of cancers, ${ }^{1-13}$ the overexpression of hCAs II and XII in glaucoma, ${ }^{14-16}$ as well as the role of CAs inhibitors (CAIs) as diuretics, antiepileptic, in the management of altitude sickness, antiobesity, diagnostic tools, painkillers, and anti-infective drugs. ${ }^{17-20}$ However, the design of isozyme specific inhibitors still remains an issue, due to the high similarity between the catalytic sites of this family of enzymes. ${ }^{2,3,8,21-25}$ Indeed, several mechanisms of inhibition have been reported and new classes of CAIs have been therefore investigated, besides the classical zinc binders.

Nevertheless, most of CAIs are generally characterized by a zinc-binding group (ZBG), which could be a sulfonamide or a bioisoster. The ZBG is often linked to a scaffold capable of interacting with one or both hydrophobic and hydrophilic halves of the active site and by a tail that may interact with the most variable sites of the enzyme such as the entrance of the cavity, thus enhancing the isoform selectivity profile of CA inhibitors. $^{25}$ Carboxylates, hydroxamates, dithiocarbamates, and isosters are included in this class. $^{26-28}$ However, the most important and largely represented $\mathrm{ZBG}$ is the sulfonamide group. Accordingly, the majority of the clinically used CAIs belong to the sulfonamide's family. They comprise acetazolamide (1), ethoxzolamide (2), sulthiame (3), dorzolamide (4) (Figure 1), and more. On the basis of the above and pursuing our research of sulfonamide based hCA inhibitors, ${ }^{29-33}$ we have synthesized a series of 4-[(3-ethyl-4aryl-2,3-dihydro-1,3-thiazol-2-ylidene) amino] benzene-1-sulfonamides (EMAC10101a-m) and evaluated their activity against the hCA I, II, IX, and XII isozymes. Compounds

Special Issue: In Memory of Maurizio Botta: His Vision of Medicinal Chemistry

Received: December 23, 2019

Accepted: February 13, 2020

Published: February 13, 2020

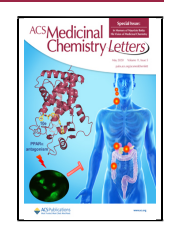




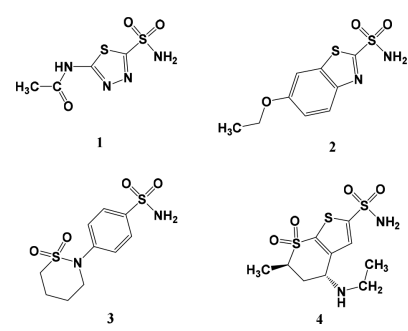

Figure 1. Examples of sulfonamides in clinical use.

\section{Scheme 1. Synthetic Pathway to Compounds} EMAC10101a-m ${ }^{a}$

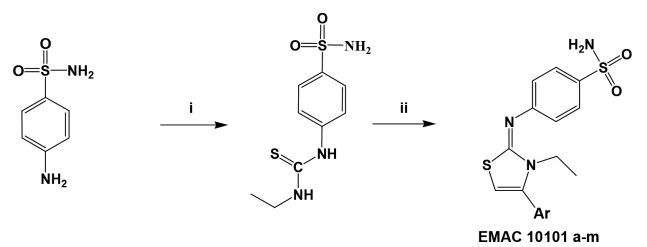

${ }^{a}$ Reagents and conditions: (i) ethyl isothiocyanate, 2-propanol, reflux; (ii), $\alpha$-halogen arylketone, $\mathrm{rt} / 80^{\circ} \mathrm{C}$.
EMAC10101a-m were synthesized by slightly modifying a previously reported procedure (Supporting Information) ${ }^{34}$ (Scheme 1).

All the obtained compounds were characterized by means of analytical and spectroscopic methods (Figures S1-S39 and Tables S1-S3) and then submitted to biological evaluation to assess their activity against hCA I, II, IX, and XII (Table 1). When tested on hCA I, none of the new derivatives exhibited activity in the nanomolar range. Only compounds EMAC10101b and EMAC10101c, bearing a 3 nitro- and a 2,4-difluorophenyl substituent, respectively, were active in the low micromolar range. Conversely, most of the EMAC compounds were active toward the hCAII isozyme in the nanomolar range. Only compounds EMAC10101a and EMAC10101h exhibited activity in the low micromolar range. Consequently, the introduction of a chlorine atom or of a nitro group in position 4 of the phenyl substituent was detrimental for the inhibition activity. When a second halogen is introduced in position 2 of the phenyl ring, the activity is restored. Thus, compounds EMAC10101c and EMAC10101d were the most potent hCA II inhibitors exhibiting $K_{\mathrm{i}}$ values of 9.2 and 8.1, respectively. The other EMAC derivatives, with

Table 1. Inhibition Data toward hCA I, II, IX, XII of Compounds EMAC10101a-m ${ }^{a}$

\begin{tabular}{|c|c|c|c|c|c|}
\hline \multirow{2}{*}{ Compound } & \multirow{2}{*}{$\mathrm{Ar}$} & \multicolumn{4}{|c|}{ Ki $(\mathrm{nM})$} \\
\hline & & hCAI & hCA II & hCA IX & hCAXII \\
\hline EMAC10101a & & 4472.4 & 724.8 & 108.8 & 1390.0 \\
\hline EMAC10101b & & 750.5 & 55.3 & 214.1 & 448.2 \\
\hline EMAC10101c & & 698.0 & 9.2 & 143.8 & 367.6 \\
\hline EMAC10101d & & 9627.4 & 8.1 & 224.6 & 154.9 \\
\hline EMAC10101e & & 9067.2 & 65.5 & 3391.0 & 1379.4 \\
\hline EMAC10101f & & 9703.4 & 90.3 & 4305.7 & 1751.4 \\
\hline EMAC10101g & & 4958.5 & 65.5 & 4333.3 & 1820.6 \\
\hline EMAC10101h & & 8720.1 & 285.3 & 4320.2 & 1795.6 \\
\hline EMAC10101i & & 2868.6 & 75.1 & 3930.0 & 1689.2 \\
\hline EMAC10101j & & 1604.2 & 60.8 & 357.7 & 157.2 \\
\hline EMAC10101k & & 8155.2 & 44.0 & 205.3 & 60.9 \\
\hline EMAC101011 & & 9625.0 & 55.1 & 297.1 & 1118.8 \\
\hline EMAC10101m & & 8622.7 & 60.9 & 247.9 & 175.1 \\
\hline AAZ & & 250 & 12.1 & 25.8 & 5.7 \\
\hline
\end{tabular}

${ }^{a}$ Values are the mean from three different assays, by a stopped flow technique (errors were in the range of $\pm 5-10 \%$ of the reported values). 


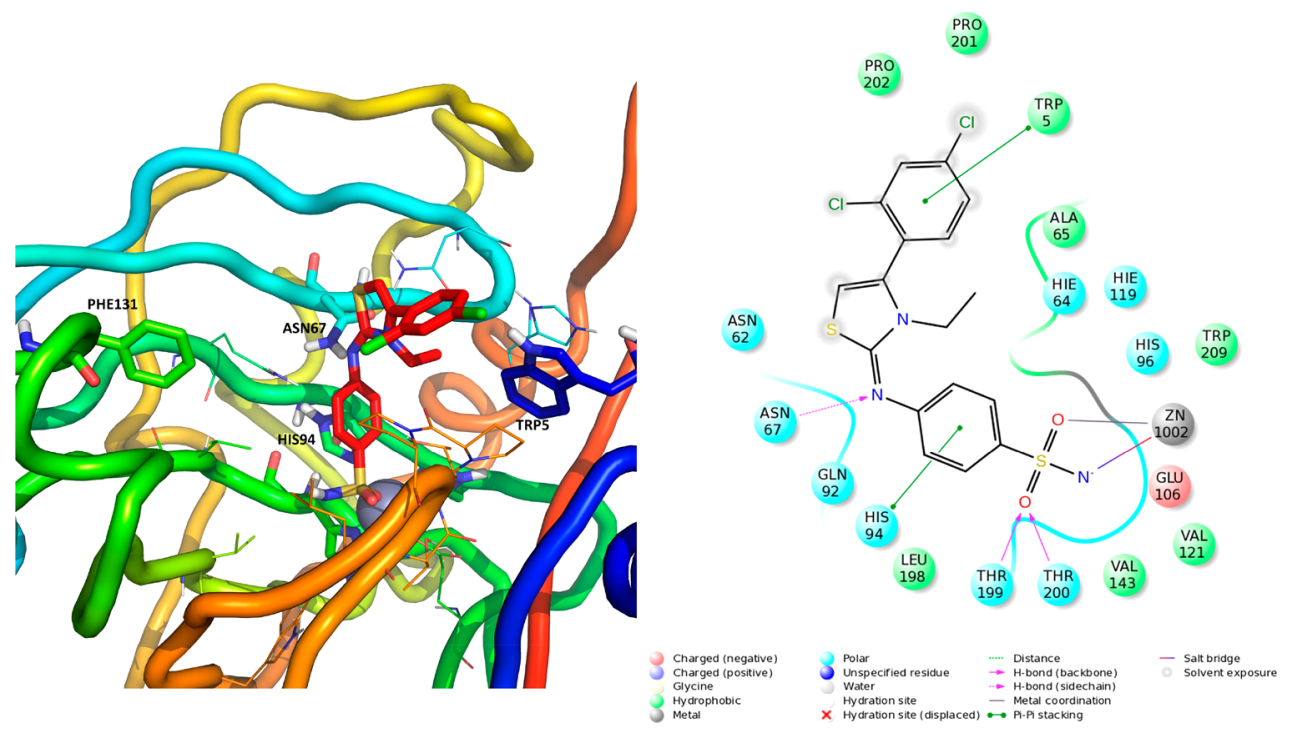

Figure 2. 3D representation of the putative binding mode obtained by docking experiment of EMAC10101d into hCA II and relative 2D representation of the complex stabilizing interactions with the binding site residues.

the exception of the above-mentioned EMAC10101a and EMAC10101h, exhibited $K_{\mathrm{i}}$ values on hCA II ranging from 44.0 to 90.3. Regarding hCA IX, only compound EMAC10101a exhibited some selectivity with a $K_{\mathrm{i}}$ value of $108.8 \mathrm{nM}$. Moreover, its $K_{\mathrm{i}}$ values toward the other hCA isozymes are $4472.4,724.8$, and 1390.0 toward hCA I, II, and XII, respectively.

Docking experiments of compound EMAC10101d into hCA II (PDB code $3 \mathrm{k} 34$ ), ${ }^{35}$ showed that the benzensulfonamide moiety is able to accommodate close to the catalytic site and chelate the $\mathrm{Zn}$ ion. Although the 4-aryl-2,3-dihydro-1,3thiazol-2-ylidene moiety is bulkier with respect to the known unselective hCA IIi (acetazolamide (1), dorzolamide (4), Figure S40a), the tail is not able to affect the selectivity toward the membrane isoforms IX and XII. Furthermore, the substitutions in position 3 of thiazolidine moiety with bulky groups was shown to be detrimental for the inhibitory activity $K_{\mathrm{i}}, \mathrm{C}_{5} \mathrm{H}_{6}>\mathrm{Et}>\mathrm{Me}{ }^{29-31}$ because of the lack of space in the binding pocket. Hence, to achieve isozyme selectivity, the optimization of these series of compounds should be directed toward the modification of the tail in order to point to more external residues that are bulkier in hCA II than in the isoforms IX and XII and in particular toward the residue Phe131 which is mutated in valine in hCA IX and alanine in XII, Figure S40b.

Overall the complex EMAC10101d is stabilized by a hydrogen bond with ASN67, which in hCA XII is substituted by a lysine, and $\pi-\pi$ interactions with HIS 94 and TRP 5 and by several hydrophobic interactions with surrounding residues. Finally, the sulfonamide moiety is anchored to the $\mathrm{Zn}^{2+}$ and residues THR199 and THR200 (Figure 2).

Small changes in the Ar ring produced activity cliffs, showing that the pocket is highly sensitive to the substituent and molecule interactions. As an example, in EMAC10101a the loss of a $\mathrm{Cl}$ caused a drop of the activity due to the loss of a hydrogen bond and contacts with surrounding residues (Figure S41, Table S4).

In conclusion our data highlighted the relevance of the dihydrothiazole benzensulfonamide scaffold for the inhibition of hCA isoforms. Moreover, indication for future isozyme selectivity optimization was achieved, thus paving the way for the design and synthesis of new derivatives with enhanced properties.

\section{ASSOCIATED CONTENT}

\section{(1) Supporting Information}

The Supporting Information is available free of charge at https://pubs.acs.org/doi/10.1021/acsmedchemlett.9b00644.

Experimental procedures and characterization of compounds (PDF)

\section{AUTHOR INFORMATION}

\section{Corresponding Authors}

Simona Distinto - Department of Life and Environmental Sciences, University of Cagliari, 09124 Cagliari, Italy; ○ orcid.org/0000-0003-1620-6225; Email: s.distinto@ unica.it

Claudiu T. Supuran - Dipartimento NEUROFARBA, Sezione di Scienze Farmaceutiche, Università degli Studi di Firenze, 50139 Florence, Italy; (i) orcid.org/0000-0003-4262-0323; Email: claudiu.supuran@unifi.it

\section{Authors}

Rita Meleddu - Department of Life and Environmental Sciences, University of Cagliari, 09124 Cagliari, Italy

Filippo Cottiglia - Department of Life and Environmental Sciences, University of Cagliari, 09124 Cagliari, Italy; (1) orcid.org/0000-0003-4659-9808

Rossella Angius - Laboratorio NMR e Tecnologie Bioanalitiche, Sardegna Ricerche, 09010 Pula, CA, Italy

Pierluigi Caboni - Department of Life and Environmental Sciences, University of Cagliari, 09124 Cagliari, Italy; (1) orcid.org/0000-0003-2448-3767

Andrea Angeli - Dipartimento NEUROFARBA, Sezione di Scienze Farmaceutiche, Università degli Studi di Firenze, 50139 Florence, Italy; 이이이.org/0000-0002-1470-7192

Claudia Melis - Department of Life and Environmental Sciences, University of Cagliari, 09124 Cagliari, Italy

Serenella Deplano - Department of Life and Environmental Sciences, University of Cagliari, 09124 Cagliari, Italy 
Stefano Alcaro - Dipartimento di Scienze della Salute, Università Magna Graecia di Catanzaro, 88100 Catanzaro, Italy

Francesco Ortuso - Dipartimento di Scienze della Salute, Università Magna Graecia di Catanzaro, 88100 Catanzaro, Italy; (i) orcid.org/0000-0001-6235-8161

Elias Maccioni - Department of Life and Environmental Sciences, University of Cagliari, 09124 Cagliari, Italy

Complete contact information is available at: https://pubs.acs.org/10.1021/acsmedchemlett.9b00644

\section{Author Contributions}

The manuscript was written through contributions of all authors. All authors have given approval to the final version of the manuscript.

\section{Notes}

The authors declare no competing financial interest.

\section{ACKNOWLEDGMENTS}

The authors acknowledge the "Ufficio Valorizzazione dei Risultati della Ricerca” of Sardegna Ricerche Technological Park, Pula (CA), Italy. The authors also thank the COST action CA15135 (Multitarget Paradigm for Innovative Ligand Identification in the Drug Discovery Process MuTaLig) for support.

\section{ABBREVIATIONS}

hCA, human carbonic anhydrase; ZBG, zinc-binding group

\section{REFERENCES}

(1) Supuran, C. T. Carbonic Anhydrases as Drug Targets: General Presentation; John Wiley \& Sons, Inc., 2009; pp 15-38.

(2) Domsic, J. F.; Avvaru, B. S.; Kim, C. U.; Gruner, S. M.; Agbandje-McKenna, M.; Silverman, D. N.; McKenna, R. Entrapment of carbon dioxide in the active site of carbonic anhydrase II. J. Biol. Chem. 2008, 283 (45), 30766-71.

(3) Horie, K.; Kawakami, K.; Fujita, Y.; Sugaya, M.; Kameyama, K.; Mizutani, K.; Deguchi, T.; Ito, M. Exosomes expressing carbonic anhydrase 9 promote angiogenesis. Biochem. Biophys. Res. Commun. 2017, 492 (3), 356-361.

(4) Nocentini, A.; Supuran, C. T. Advances in the structural annotation of human carbonic anhydrases and impact on future drug discovery. Expert Opin. Drug Discovery 2019, 14 (11), 1175-1197.

(5) Supuran, C. T. Carbonic anhydrases: novel therapeutic applications for inhibitors and activators. Nat. Rev. Drug Discovery 2008, 7 (2), 168-181.

(6) Supuran, C. T. Structure and function of carbonic anhydrases. Biochem. J. 2016, 473 (14), 2023-32.

(7) Supuran, C. T.; Winum, J.-Y. Carbonic anhydrase IX inhibitors in cancer therapy: an update. Future Med. Chem. 2015, 7 (11), 14071414.

(8) Zhou, Y.; Mokhtari, R. B.; Pan, J.; Cutz, E.; Yeger, H. Carbonic Anhydrase II Mediates Malignant Behavior of Pulmonary Neuroendocrine Tumors. Am. J. Respir. Cell Mol. Biol. 2015, 52 (2), 183-92.

(9) McKenna, R. Carbonic Anhydrase: Its Inhibitors and Activators. CRC Enzyme Inhibitors Series, Volume 1, Edited by Claudiu T. Supuran, Andrea Scozzafava, and Janet Conway. J. Am. Chem. Soc. 2005, 127 (10), 3643.

(10) Nocentini, A.; Supuran, C. T., Carbonic anhydrases: an overview. In Carbonic Anhydrases; Supuran, C. T., Nocentini, A., Eds.; Academic Press,: 2019; Chapter 1, pp 3-16.

(11) Alafeefy, A. M.; Ahmad, R.; Abdulla, M.; Eldehna, W. M.; AlTamimi, A.-M. S.; Abdel-Aziz, H. A.; Al-Obaid, O.; Carta, F.; AlKahtani, A. A.; Supuran, C. T. Development of certain new 2- substituted-quinazolin-4-yl-aminobenzenesulfonamide as potential antitumor agents. Eur. J. Med. Chem. 2016, 109, 247-253.

(12) Ibrahim, H. S.; Abou-Seri, S. M.; Tanc, M.; Elaasser, M. M.; Abdel-Aziz, H. A.; Supuran, C. T. Isatin-pyrazole benzenesulfonamide hybrids potently inhibit tumor-associated carbonic anhydrase isoforms IX and XII. Eur. J. Med. Chem. 2015, 103, 583-593.

(13) Supuran, C. T. Inhibition of carbonic anhydrase IX as a novel anticancer mechanism. World J. Clin. Oncol. 2012, 3 (7), 98-103.

(14) Maren, T. H. Carbonic anhydrase: General perspective and advances in glaucoma research. Drug Dev. Res. 1987, 10 (4), 255276.

(15) Scozzafava, A.; Supuran, C. T. Glaucoma and the applications of carbonic anhydrase inhibitors. Subcell. Biochem. 2014, 75, 349-59.

(16) Silver, L. H. Clinical efficacy and safety of brinzolamide (Azopt), a new topical carbonic anhydrase inhibitor for primary openangle glaucoma and ocular hypertension. Am. J. Ophthalmol. 1998, 126 (3), 400-408.

(17) Carta, F.; Supuran, C. T. Diuretics with carbonic anhydrase inhibitory action: a patent and literature review (2005 - 2013). Expert Opin. Ther. Pat. 2013, 23 (6), 681-691.

(18) De Simone, G.; Di Fiore, A.; Supuran, C. T. Are carbonic anhydrase inhibitors suitable for obtaining antiobesity drugs? Curr. Pharm. Des. 2008, 14 (7), 655-660.

(19) Supuran, C. T. Carbonic anhydrase inhibitors as emerging drugs for the treatment of obesity. Expert Opin. Emerging Drugs 2012, 17 (1), 11-5.

(20) Thiry, A.; Dogne, J. M.; Supuran, C. T.; Masereel, B. Anticonvulsant sulfonamides/sulfamates/sulfamides with carbonic anhydrase inhibitory activity: drug design and mechanism of action. Curr. Pharm. Des. 2008, 14 (7), 661-71.

(21) Bozdag, M.; Ferraroni, M.; Nuti, E.; Vullo, D.; Rossello, A.; Carta, F.; Scozzafava, A.; Supuran, C. T. Combining the tail and the ring approaches for obtaining potent and isoform-selective carbonic anhydrase inhibitors: Solution and X-ray crystallographic studies. Bioorg. Med. Chem. 2014, 22 (1), 334-340.

(22) De Simone, G.; Alterio, V.; Supuran, C. T. Exploiting the hydrophobic and hydrophilic binding sites for designing carbonic anhydrase inhibitors. Expert Opin. Drug Discovery 2013, 8 (7), 793810.

(23) Nocentini, A.; Donald, W. A.; Supuran, C. T., Human carbonic anhydrases: tissue distribution, physiological role, and druggability. In Carbonic Anhydrases; Supuran, C. T., Nocentini, A., Eds.; Academic Press, 2019; Chapter 8, pp 151-185.

(24) Supuran, C. T. Structure-based drug discovery of carbonic anhydrase inhibitors. J. Enzyme Inhib. Med. Chem. 2012, 27 (6), 75972.

(25) Supuran, C. T. How many carbonic anhydrase inhibition mechanisms exist? J. Enzyme Inhib. Med. Chem. 2016, 31 (3), 345-60.

(26) Carta, F.; Aggarwal, M.; Maresca, A.; Scozzafava, A.; McKenna, R.; Supuran, C. T. Dithiocarbamates: a new class of carbonic anhydrase inhibitors. Crystallographic and kinetic investigations. Chem. Commun. 2012, 48 (13), 1868-1870.

(27) Innocenti, A.; Vullo, D.; Scozzafava, A.; Casey, J. R.; Supuran, C. Carbonic anhydrase inhibitors. Interaction of isozymes I, II, IV, V, and IX with carboxylates. Bioorg. Med. Chem. Lett. 2005, 15 (3), 573578 .

(28) Supuran, C. T. Hydroxamates as Carbonic Anhydrase Inhibitors. In Hydroxamic Acids: A Unique Family of Chemicals with Multiple Biological Activities; Gupta, S. P., Ed.; Springer: Berlin, 2013; pp 55-69.

(29) Bianco, G.; Meleddu, R.; Distinto, S.; Cottiglia, F.; Gaspari, M.; Melis, C.; Corona, A.; Angius, R.; Angeli, A.; Taverna, D.; Alcaro, S.; Leitans, J.; Kazaks, A.; Tars, K.; Supuran, C. T.; Maccioni, E. NAcylbenzenesulfonamide Dihydro-1,3,4-oxadiazole Hybrids: Seeking Selectivity toward Carbonic Anhydrase Isoforms. ACS Med. Chem. Lett. 2017, 8 (8), 792-796.

(30) Distinto, S.; Meleddu, R.; Ortuso, F.; Cottiglia, F.; Deplano, S.; Sequeira, L.; Melis, C.; Fois, B.; Angeli, A.; Capasso, C.; Angius, R.; Alcaro, S.; Supuran, C. T.; Maccioni, E. Exploring new structural 
features of the 4-[(3-methyl-4-aryl-2,3-dihydro-1,3-thiazol-2-ylidene)amino] benzenesulphonamide scaffold for the inhibition of human carbonic anhydrases. J. Enzyme Inhib. Med. Chem. 2019, 34 (1), $1526-1533$.

(31) Meleddu, R.; Distinto, S.; Cottiglia, F.; Angius, R.; Gaspari, M.; Taverna, D.; Melis, C.; Angeli, A.; Bianco, G.; Deplano, S.; Fois, B.; Del Prete, S.; Capasso, C.; Alcaro, S.; Ortuso, F.; Yanez, M.; Supuran, C. T.; Maccioni, E. Tuning the Dual Inhibition of Carbonic Anhydrase and Cyclooxygenase by Dihydrothiazole Benzensulfonamides. ACS Med. Chem. Lett. 2018, 9 (10), 1045-1050.

(32) Meleddu, R.; Maccioni, E.; Distinto, S.; Bianco, G.; Melis, C.; Alcaro, S.; Cottiglia, F.; Ceruso, M.; Supuran, C. T. New 4-[(3cyclohexyl-4-aryl-2,3-dihydro-1,3-thiazol-2-ylidene)amino]benzene-1sulfonamides, synthesis and inhibitory activity toward carbonic anhydrase I, II, IX, XII. Bioorg. Med. Chem. Lett. 2015, 25 (16), 3281-3284.

(33) Melis, C.; Meleddu, R.; Angeli, A.; Distinto, S.; Bianco, G.; Capasso, C.; Cottiglia, F.; Angius, R.; Supuran, C. T.; Maccioni, E. Isatin: A privileged scaffold for the design of carbonic anhydrase inhibitors. J. Enzyme Inhib. Med. Chem. 2017, 32 (1), 68-73.

(34) Meleddu, R.; Distinto, S.; Corona, A.; Tramontano, E.; Bianco, G.; Melis, C.; Cottiglia, F.; Maccioni, E. Isatin thiazoline hybrids as dual inhibitors of HIV-1 reverse transcriptase. J. Enzyme Inhib. Med. Chem. 2017, 32 (1), 130-136.

(35) Behnke, C. A.; Le Trong, I.; Godden, J. W.; Merritt, E. A.; Teller, D. C.; Bajorath, J.; Stenkamp, R. E. Atomic resolution studies of carbonic anhydrase II. Acta Crystallogr., Sect. D: Biol. Crystallogr. 2010, 66 (Part5), 616-627. 